\title{
Evaluation of low cost radiant cooling panel in a test room with passively cooled water
}

\author{
Muhammad Syukri Imran ${ }^{1^{*}}$, Azhaili Baharun ${ }^{2}$, Siti HalipahIbrahim ${ }^{3}$, Wan Azlan Wan \\ Zainal Abidin 4
}

\author{
1, 2, 3, 4 Universiti Malaysia Sarawak, Kota Samarahan, Malaysia
}

\author{
Index Terms \\ Radiant Cooling Panel \\ Energy Savings \\ Thermal Comfort \\ Cooling Capacity \\ PVC Tube
}

Received: 31 August 2016

Accepted: 15 May 2017

Published: 9 October 2017

\begin{abstract}
Public acceptance in low energy hydronic radiant cooling system is almost none in country like Malaysia. This is due to the low awareness of the performance and benefit of such system in the country as well as higher initial construction cost. With the aim of long term energy and cost saving this study looks into the performance of custom built radiant cooling surface panel that was retrofitted in a test room located in Kuching Sarawak. In climate condition like Malaysia where only cooling is required, the radiant panel needs only to be a cooling surface unlike its overseas counterpart that heats or cools interchangeably according to the changing seasons. This allows the use of alternative low cost material such as PVC to replace the more common radiant tubing like copper or cross-linked Polyethylene (PEX) tube. A test room was retrofitted with PVC tubing radiant ceiling panel and connected to a chill water tank. The water was passively cooled during the night using the pitch roof as a heat exchanger to chill the water to as low as $24^{\circ} \mathrm{C}$. The water was then used to charge the hydronic ceiling radiant panel during the day time when the outdoor temperature exceeds $30^{\circ} \mathrm{C}$. The experiment shows that the system was able to maintain an indoor temperature to about $30^{\circ} \mathrm{C}$ when the outdoor temperature peaked to $34^{\circ} \mathrm{C}$ while providing acceptable thermal comfort. The experiment showed that the use of the hydronic radiant panel with free night cooled water as its coolant have significant energy saving potential while at the same time provide an acceptable room thermal comfort. The locally built radiant panel and easy to install night cooling rig could be an attractive choice as a Malaysian building cooling system that complies to a bioclimatic building principle.
\end{abstract}

(C) 2017 The Author(s). Published by TAF Publishing.

\section{INTRODUCTION}

In the modern world society, sustainability has become crucial element in building development. Thus it has become necessary for building designer or developers to design building according to bioclimatic principles. A balance in the relationship between the home occupants, the housing and climate defines the sustainability that is required for a bioclimatic housing. Some input measures in bioclimatic housing includes use of passive systems rather than active mechanical systems, renewable energy systems, sustainable materials and water as well as integration of passive system through integration of microclimate and ac- tive system [1]. The given measures normally are aimed to improve the comfort and wellbeing of occupants, reduce environmental impact as well as reduction of cost over life cycle period. Focus is now given in resource conservation and applying new technology to help climate adapt or responsive to natural condition. This technique to use new technology to enhance or amplify bioclimatic have become the latest trend in architecture as humans are required to adapt to a rapidly warming world [2]. Energy demanding air conditioning is seen as a part of the climate change problem as the energy used to run the systems contributes to greenhouse emissions therefore give rise to adoption of more effective methods of passively cooling buildings while con-

\footnotetext{
${ }^{*}$ Corresponding author: Muhammad Syukri Imran

†Email: 14010080@siswa.unimas.my
} 
serving energy. There exist opportunity to integrate passive and active system to improve thermal comfort as well as to gain benefits of reduced energy consumption particularly in Malaysia. Hydronic radiant cooling system which is a type of building heating and cooling system appliance is known to provide $12 \%$ to $18 \%$ energy reduction in comparison to a convective system like air conditioning while providing equivalent comfort [3]. A futher $80 \%$ to $90 \%$ is feasible if the radiant cooling system were to combined with a renewable coolant rather than using a mechanical chiller to provide chill water as the cooling medium for the radiant system [4]. This is possible as traditional chillers can be eliminated and only electricity for circulation pumps is needed. Chill water temperature between $12.7^{\circ} \mathrm{C}$ to $17.2^{\circ} \mathrm{C}$ is the typical temperature for a hydronic radiant cooling system. However due to dew point and condensation restriction in hot and humid climate, the hydronic radiant system is restricted to higher water temperature operation range of between $20^{\circ} \mathrm{C}$ to $25^{\circ} \mathrm{C}$ or otherwise the use of a desiccant dehumidification is deemed to be necessary [5]. Ideal water temperature to be used in this region is in the range of $20^{\circ} \mathrm{C}$ to $25^{\circ} \mathrm{C}$ and in Malaysian climate the yearly minimum temperature or the night sky could provide such cooling source.

\section{A. Objective of the Study}

The objective of this study is to evaluate the energy usage and indoor thermal comfort of a test room installed with active low cost radiant cooling ceiling panel combined with passive night cooled water as part of bioclimatic enhancement of a local Malaysian building.

\section{LITERATURE REVIEW}

According to a bioclimatic principle, building should adapt measures which include passive systems in the design of the building with the aim to reduce environmental impacts and reduction of cost while not forgetting the thermal comfort or wellbeing of occupants [1]. From this standpoint, alternative methods are explored and tested in place of the traditional habits particularly in building cooling method. The cool night sky or the cool ground for example could be used as a natural heat sink to cool down building [6]. Air or water could be used as a cooling medium to transport the indoor heat from the building and discharge the heat to a cooler body such as the night sky or the cooler ground [7]. In some instances water is used as a thermal storage where the water is cooled down by the natural heat sink source and is kept in an insulated water tanks for use at a later time. The stored chill water may be supplied to a heat exchanger such as a radiant panel during the day time to cool down the building.

There are several ways or device that could be used to cool the water under the night sky to take advantage of the night radiation including evaporation and conduction heat loss effect. Literature survey have found studies with regards to night cooling done by others such as water flowing under flat plate collector [8], open tank experiment [9], water flowing openly over solar collector [10], thermosyphon heat pipe radiator cooling [11], roof pond experiment [12], converted flat plate solar collectors [13], thermal absorber with water pipes numerical analysis [14], hybrid nocturnal radiative cooling and direct evaporative cooling test $[15,16]$, piped nocturnal radiator with phase change material or PCM [17], solar water heater absorber test [18] and others. Study by Azhaili et al. [19] have shown that water temperature in the morning after a night cooling process by trickling water over roof could reach lower than $25^{\circ} \mathrm{C}$ in Malaysian region. The process only requires minimum pumping energy therefore greatly reduce the energy consumption in comparison to a mechanical chiller which primarily supplies chill water to certain heat exchanger such as radiant cooling panel. This renewable night cooled water supply could be used as alternative cooling medium for indoor building cooling which uses radiant surface as its heat exchanger.

Radiant system is used to condition space so that it produces a selected air temperature much like a traditional convection system or air system does. The objective is to save energy or to overcome adverse local comfort condition [3]. In this system, building surface is converted to radiant heat transfer panel that can be used for heating or cooling application. The radiant heat transfer does not directly affect the room air temperature. The long wave radiation heats or cools the surrounding surfaces, which then indirectly heats or cools the room air. A radiant cooling system basically consists of heat absorbing surface, chill water supply as the cooling medium, distribution pipe and control system. Some are integrated with building structure or embedded surface system and some are in the form of panel system with open air gap.

Radiant panel cooling system is still considered uncommon and unpopular in Malaysia. Its application in this part of the world is still rare due to various factors that hinders the development of radiant cooling system such as lack 
of local manufacturer, suppliers and the high risk of surface condensation of cooling panel in this tropical hot and humid climate [20]. Public acceptance in low energy hydronic radiant cooling system is very low in country like Malaysia. This is due to the low awareness of the performance and benefit of such system with only a few government initiated projects such as the Malaysian Energy Commission building and Malaysian Green Technology Corporation building. Not to mention the initial construction cost for the system is generally higher than air system due to unavailability of local manufacturers with limited architects or engineers who are familiar in the system. Experiment by Imran, Ibrahim, Baharun \& Abidin [21] showed that cheaper and workable radiant cooling panel can be constructed with local materials that serves as an alternative to imported and expensive radiant cooling panels. The importing of overseas radiant cooling panel or components and fixtures normally consisting copper tube or cross linked Polyethylene (PEX) pipe would incur such a heavy cost especially with the depreciat- ing RM currency. Therefore in this study, custom build low cost panel shall be constructed to convert indoor surfaces into cooling surfaces.

\section{METHODOLOGY}

\section{A. Experimental Set Up}

The test was carried out in a 5 feet by 8 feet test room which is part of a typical semidetached house located in Kuching, Sarawak (1.612704 latitude, 110.335705 longitude) during the hot month of June. Kuching city experiences hot and humid climate all year with hotter season takes place normally between the month of April and July. An illustration of the experimental setup is shown in Figure 1. Another identical room which is available in the house having the same dimensions and construction was used as a control room in the experiment. Both rooms have a small window opening of 2 feet by 3 feet.

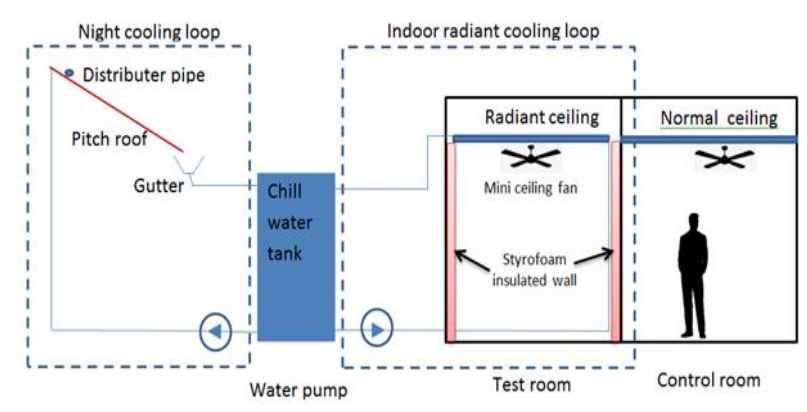

Fig. 1. Experimental set-up for indoor cooling with night cooled water

The test rig consists of night cooling loop and indoor cooling loop. For the night cooling loop, the existing 25 feet by 19 feet steel roof structure was used as a heat exchanger to cool water at night via a combination of evaporative, radiative and convective cooling. The chill water was stored in insulated double 200 gallon HDPE tank and was later used as cooling medium for the indoor radiant cooling loop. The hydronic radiant ceiling panel is connected to the chill water tank so that it uses chill water as its cooling medium to cool the ceiling panel surfaces. Figure 2 shows the chill water storage tanks which were located near the steel roof structure. Two water pumps of at least $1 \mathrm{HP}$ each were provided for each loop so that water could be circulated at night for cooling purpose as well as during the day time when operating the radiant cooling panels. Sizing of the pumps were based on calculation results by thermal energy modelling software Energy Plus.

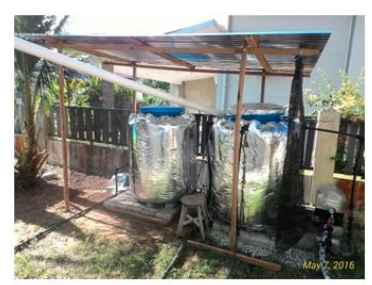

(a) 2 units of 200 gallon insulated water storage tanks with pump set

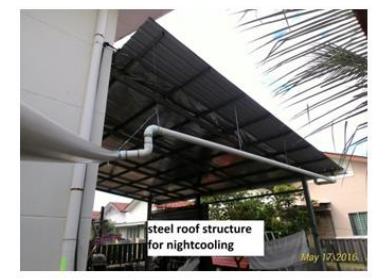

(b) Pitch steel roof structure acting as a heat exchanger to cool water at night time
Fig. 2. Chill water tank and pitch roof structure connection

The ceiling panels were located about $10 \mathrm{ft}$ from the floor and were painted black in colour to optimize the heat transfer process. Black painted surface is considered as having the best heat absorptivity as it applies in this case. The absorptivity of a surface is defined as the fraction of energy incident on a surface that is actually absorb by that surface [3] . Another type of radiation properties other than ab- 
sorptivity is the emissivity of a surface. This is the measure of how well that surface emits radiation energy relative to a black body with value between one and zero. According to Kirchhorff's law both radiation properties (absorptivity and emissivity) are equal. Because of this the same surface can be used as heat radiators for indoor heating purpose. Most building construction material or non-metals have high surface emittance of 0.9 or greater whereas polished aluminium surface is very reflective therefore has a low surface emittance of 0.03 or lower. If aluminium surface were used it should be painted so that it will have the radiative properties of the paint which is generally higher than 0.8. Figure 3 shows the radiant ceiling panels in cloud configuration which covered almost $90 \%$ of the total ceiling area. A mini fan was installed in the middle to create a forced air movement in the room when required.

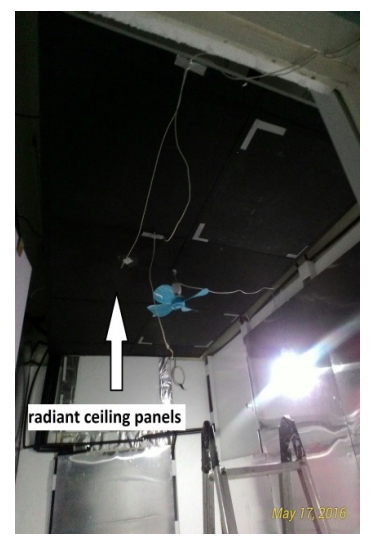

Fig. 3 . Test room with radiant ceiling panels and mini ceiling fan installed

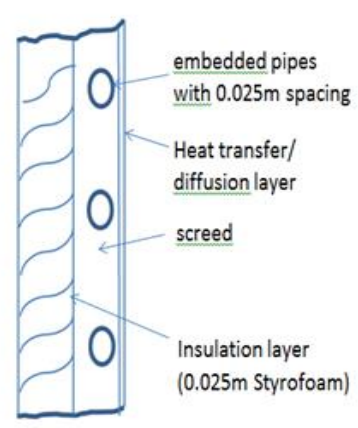

(a) Cross section of ceiling radiant panel.
The experiment was conducted under forced air movement condition which was provided by the mini fan. The fan has a power rating of $18 \mathrm{~W}$ and could provide air speed of 1.2 $\mathrm{m} / \mathrm{s}$ or greater at $67 \mathrm{inch}$ from the floor level. All 4 sides of the wall were insulated with 1 inch expanded polystyrene or Styrofoam and lined with aluminium sheet to reduce the flow of external or 'outside' heat flux through the walls and into the test room. The test room window was also covered with an aluminium reflective sheet to deter the short wave and long wave heat radiation from the sun and the outside surrounding. This arrangement was done to ensure optimum performance of the radiant cooling panel where radiant heat exchange would occur between the cool surface of the radiant panel and other surfaces of the test room such as the wall and floor. As for the radiant panels, it was constructed using locally available material and self-assembled. Figure 4 shows the cross section view of the modular panel that will form the ceiling cooling surface in the test room. A 2 feet by 2 feet cement board which is a typical building material was used as the diffusion layer of the panel. PVC tubing was attached to the panel and was fully embedded in screed before being covered by a backside layer of Styrofoam to reduce panel back loss. Since the panel was only to be used for cooling purpose, PVC tubing was selected as it have been shown that it can perform and provide almost similar output to that of copper or PEX based panel [21] as well as cheaper to fabricate. To increase panel efficiency as well as reduce resistance between cooling element and radiating surface, gypsum plaster was used as screed to bond the tubing and the diffusion layer.

Fig. 4 . Section and back side view of the custom made cooling radiant panel construction

(b) $2 \mathrm{ft} \times 2 \mathrm{ft}$ cement board as ceiling panels with PVC tubing layout

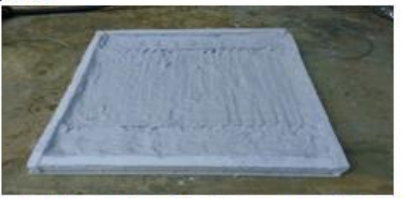

(c) Tubing fully embedded in screed layer. 


\section{B. Evaluation Of Comfort}

For a mechanically condition space, prediction of thermal comfort requires environmental measurement which include the occupant Metabolic Rate (MET), occupants Clothing Insulation Value (CLO), air temperature, Relative Humidity (RH), Mean Radiant Temperature (MRT) as well as air speed [22]. American Society of Heating, Refrigerating, and Air-Conditioning Engineers (ASHRAE) Standard 55 require that the air speed and average air temperature was measured at the centre of the room at 4", 24", 43 " and 67" high from the floor. It was also stated in the standard that measurement be taken at least for 2 hours during period deem to be critical hours during the day. The measurement data taken was then evaluated using Predicted Mean Vote (PMV) and Standard Effective Temperature (SET) comfort zone defined by Section 5.3.1 and 5.3.3 in the standard. The standard also specified that the calculation of PMV shall be done at the 24" and 43" level which corresponds to both seated and standing occupant in the room.

PMV is a theoretical method to predict thermal comfort of a large group of people in a thermal environment. Generally thermal comfort surveys involves subject giving rating to their thermal environment on a seven point scale from cold (-3) to hot (+3). PMV predicts the mean vote of such survey by using equation which takes into account of six thermal comfort parameters such as air movement, MRT, air temperature, RH, metabolic rate and clothing insulation. The last two parameters are characteristic of the occupants while the others are environmental condition.
Predicted Percentage of Dissatisfied (PPD) is an empirical model index which is used to quantify the percentage of thermally dissatisfied people who are feeling too cool or too warm [23]. ASHRAE specified that at least $80 \%$ of people be satisfied for PMV between -0.5 and +0.5 on the thermal sensation scale for compliance. To determine the thermal comfort of an occupied space, ASHRAE provides methods such as graphic comfort zone as well as analytical comfort zone method. The graphical method displays the comfort zone on a psychrometric or a temperature-relative humidity chart showing the acceptable range of operative temperature and humidity. However this method is applicable to air speed up to $0.2 \mathrm{~m} / \mathrm{s}$ and metabolic rate of not more than 1.3. On the other hand the analytical method allows the use of ASHRAE Thermal Comfort Tool (TCT) a computer program to determine the thermal comfort of an occupied space. Other computer program is permissible to be used provided that it has been checked against ASHRAE TCT results. This method could be used for metabolic rates between 1.0 and 2.0. ASHRAE TCT also includes Standard Effective Temperature (SET) model which is used to evaluate thermal comfort case with air movement greater than $0.2 \mathrm{~m} / \mathrm{s}$. A sample of SET calculated result is shown in Figure 5. The bounded area shows the acceptable range of operative temperature and air speed of up to $1.2 \mathrm{~m} / \mathrm{s}$ for given clothing insulation value and metabolic rate value as indicated in the figure. This model accounts for higher air movement that could provide cooling effect to people. The elevated air movement increases the maximum temperature or operative temperature range as shown by the bounded area.

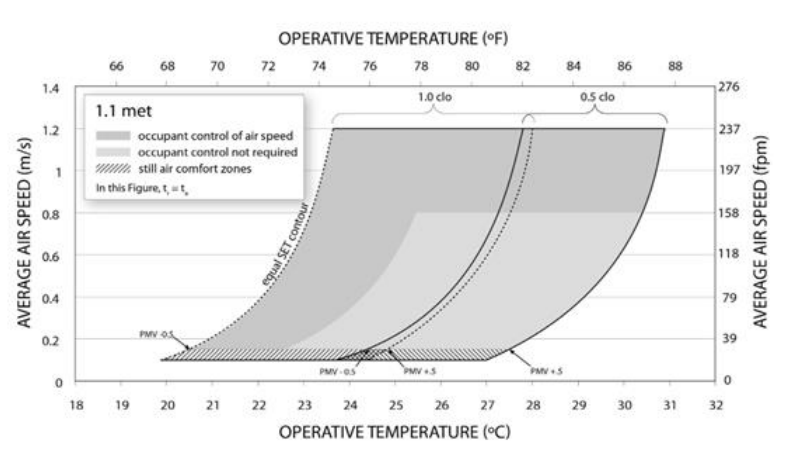

Fig. 5 . Acceptable ranges of operative temperature and average air speed for 1.0 and 0.5 CLO

Analytical method was applied in this study as the expected air movement is greater than $0.2 \mathrm{~m} / \mathrm{s}$ in the test room by way of ceiling fan that was used in the study. Centre for the Built Environment (CBE) thermal comfort tool soft- ware was used in this study to evaluate the thermal comfort condition of the test room and could be downloaded as a non-commercial license application from the website [24]. The work process of inputting value in the thermal comfort 
tool software is explained in Appendix G of ASHRAE Standard 55 that shows how the adjusted final PMV is derived.

8 channel data logger with type $K$ thermocouple with $0.5^{\circ} \mathrm{C}$ accuracy was used for measuring the average air temperature in the test room at the specified heights from the floors at every 5 minutes interval. The data logger was also used to measure the surface temperature of the radiant panels. A globe thermometer was used in combination with shielded air temperature reading to calculate MRT. The following formula shall be used to convert globe to MRT [25]; $M R T=\left[(G T+273)^{4}+2.5 \times 10^{8} \times v_{a}^{0.6}\left(G T-T_{a}\right)\right]^{4}-273(1)$ Where

$M R T=$ Mean Radiant Temperature $\left({ }^{0} \mathrm{C}\right)$

$G T=$ Globe Temperature $\left({ }^{\circ} \mathrm{C}\right)$

$v_{a}=$ air velocity at level of globe $(\mathrm{m} / \mathrm{s})$

$T_{a}=$ Air temperature $\left({ }^{0} \mathrm{C}\right)$

The operative temperature could then be calculated by averaging the MRT and shielded air temperature reading. Another separate data logging instrument was also used to measure the shielded air temperature as well as the RH in the test room. All the above mentioned parameters are required in the prediction of comfort according to PMV based comfort zone for a given occupant clothing and metabolic rate.

As the first step, the indoor air temperature for both the test room as well as control room was measured on a typical hot day before the installation of the radiant cooling system. This is to show that both the test room and control room should have about the same thermal condition if not exactly the same prior to the introduction of a radiant cooling system. After the installation of the radiant cooling ceiling and including the insulation work of the test room, environmental measurements were conducted on the test room as well as the control room to determine the resulting PMV.

\section{RESULTS AND DISCUSSION}

Figure 6 shows the mean air temperature of the test room and the control room conducted on the $18^{\text {th }}$ April 2016. As the test room and control room were located next to each other and were located at the same region in the house plan, it was expected that both rooms would exhibit similar indoor thermal condition. This is true as was shown by the site air temperature measurement. The similarity of the dimension as well as the construction type of the room further explains this equal thermal condition. The peak indoor temperature took place at around $5 \mathrm{pm}$ and has a time lag of several hours behind the outdoor peak temperature which happens at around noon. Building with higher mass construction has the capacity to reduce as well as delay the peak indoor temperature of the building for several hours by storing the heat in mass and re-radiate back to the space at night [26]. For lightweight construction, the peak temperature tends to be higher and with smaller time lag. The radiant cooling ceiling panel was decided to be operated between $4 \mathrm{pm}$ and $7 \mathrm{pm}$ as this was the critical time during which the indoor temperature is at its peak. The calculated PMV for this critical time in general was 2.3 given the peak air temperature of $31.9^{\circ} \mathrm{C}, 85 \%$ humidity, still air speed of $0.15 \mathrm{~m} / \mathrm{s}$, metabolic rate of $1.2 \mathrm{met}$ and clothing insulation of 0.3 CLO. If still air speed were to increase to $1.2 \mathrm{~m} / \mathrm{s}$ by mean of a ceiling fan, the resulting PMV would still be high at about 1.1. These PMV values shall be used as the base case value for comparing to the resulting PMV value after the installation of the radiant ceiling system.

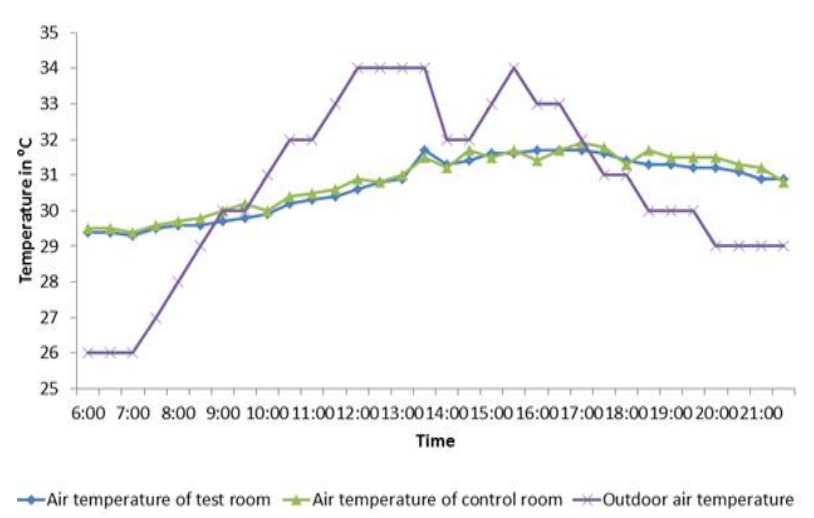

Fig. 6. Comparison of room air temperature for test and control room taken on $18^{\text {th }}$ April 2016

By end of June 2016, the ceiling radiant panel installation work including the insulation work of the wall surface was completed. The night cooling loop was operated on the night of 30th June 2016 from $7 \mathrm{pm}$ to $7 \mathrm{am}$ to cool the tank water via night cooling process. The temperature of the chill water after the night cooling process was about $25^{\circ} \mathrm{C}$. The final water temperature that could be achieved in region like Kuching Sarawak are very much dependent on the local climatic factor such as the outdoor air dry bulb temperature, wind speed, relative humidity as well as night sky cover [27]. On the $1^{\text {st }}$ July 2016 , the water pump was switched on between $4.00 \mathrm{pm}$ and $7.30 \mathrm{pm}$ so that the chill water from the chill water tank could be circulated to the indoor radiant ceiling panel. This was also the time when the indoor temperature starts to peak as explained earlier in Figure 6. 


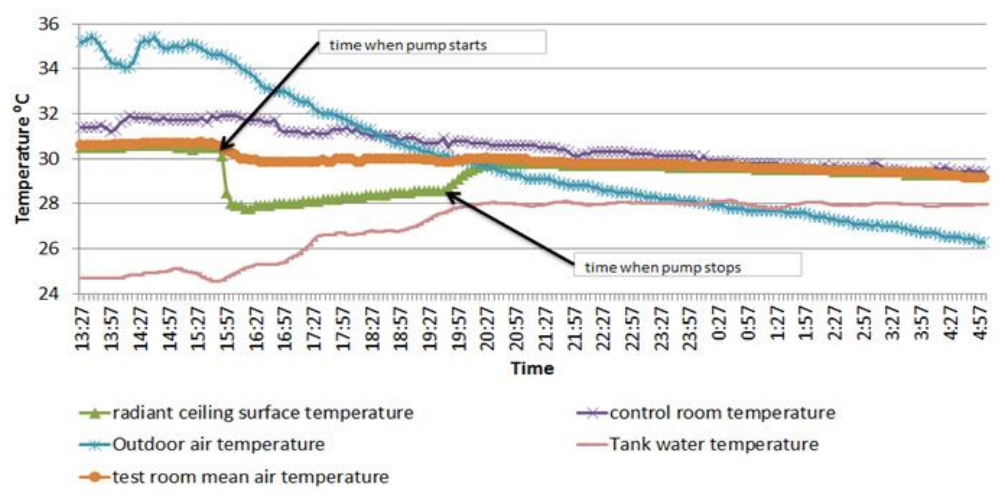

Fig. 7 . Effect of radiant ceiling panel operated with forced air movement in the test room on $1^{\text {st }}$ July 2016

The ceiling fan was operated about the same time to allow for forced air movement in the test room. Figure 7 shows the drop in surface temperature of the ceiling radiant panel after the pump was turned on. The radiant ceiling panel surface temperature had drop from $30.5^{\circ} \mathrm{C}$ to about $28^{\circ} \mathrm{C}$ when the chill water was circulated through it. This in turn has caused the test room mean air temperature to slightly drop about $0.9^{\circ} \mathrm{C}$ from $30.7^{\circ} \mathrm{C}$ to $29.8^{\circ} \mathrm{C}$. The test room temperature was able to maintain air temperature close to $30^{\circ} \mathrm{C}$ while the control room remained greater than $31^{\circ} \mathrm{C}$ during the pump operation time. The control room was seen as having failed to meet the thermal comfort limits set by ASHRAE Standard 55 as well as ISO 7730. This is in agreement with investigation by other local researcher such as [28, 29, 30, 31, 32] as well as [33] that have showed that typical Malaysian residential house including low income house failed to provide the minimum thermal comfort target. Study by [34] in a similar regional condition located in Sabah Malaysia have shown from a survey that the thermal comfort temperature was at $30.2^{\circ} \mathrm{C}$. Another study by [35] has given an upper limit of $30.7^{\circ} \mathrm{C}$ for an unconditioned building in Malaysia. Similarly study by [36] have put not more than $30^{\circ} \mathrm{C}$ as an upper limit for building in a hot and humid region. In short the control room did not satisfy both the international standard as well as the local research findings. It was also noted that the air temperature of test room in general was lower than the control room prior to the operation of the radiant cooling ceiling. This was due to the insulation layer provided to the walls of the test room as well as the reflective sheet covered window which block the radiation of the sun and the external surrounding from entering the test room. It was observed that the air temperature in the test room showed overall significant improvement as a result from the insulation work done as well as from using the radiant ceiling panel.

To determine the PMV value for the test room, environmental variable such as air temperature, mean radiant temperature, humidity and air speed was measured. Table 1 shows the summary of the measurement taken for all the said parameter during the cooling mode. It was noted that the air speed increased as the measurement height was nearer to the ceiling fan.

TABLE 1

SUMMARY OF MEASURED ENVIRONMENTAL VARIABLE FOR CALCULATING THE PMV OF TEST ROOM (AVERAGED VALUE FOR DURATION OF TEST)

\begin{tabular}{lcccc}
\hline \hline Site Measured Parameters & \multicolumn{4}{c}{ Height above Floor in Inch } \\
\cline { 2 - 5 } & $67 "$ & $43^{\prime \prime}$ & $24 "$ & $4 "$ \\
\hline Average air speed in m/s & 1.2 & 0.9 & 0.4 & 0.15 \\
Average air temperature in ${ }^{0} \mathrm{C}$ & 29.9 & 29.9 & 29.9 & 29.9 \\
Average humidity in \% & 85 & 85 & 85 & 85 \\
Average MRT in ${ }^{0} \mathrm{C}$ (from Equation. 1) & 30.0 & 30.0 & 30.0 & 30.0 \\
\hline \hline
\end{tabular}

Table 2 show the calculated PMV value using the CBE thermal comfort tool software. Result is presented for both standing occupant level (43" from floor level) and seated oc- cupant level (24" from floor level) as specified by ASHRAE Standard 55. The cooling hours provided by the radiant system was between $5 \mathrm{pm}$ to $7 \mathrm{pm}$ therefore this duration was 
evaluated for the corresponding PMV. To better visualize the preceding Tables, Figure 8 represents the graphical repre- sentation of the case mentioned above as computed according to SET model.

TABLE 2

CALCULATED PMV FOR CLOTHING INSULATION VALUE BETWEEN 0.3 AND 0.5 AT STANDING AND SEATED OCCUPANT LEVEL

\begin{tabular}{lcccc}
\hline \hline Thermal Comfort Parameter & \multicolumn{2}{c}{ Standing Occupant Level } & \multicolumn{2}{c}{ Seated Occupant Level } \\
\hline Metabolic rate & 1.2 & 1.2 & 1.2 & 1.2 \\
Clothing insulation value & 0.3 & 0.5 & 0.3 & 0.5 \\
Average operative temperature, ${ }^{\circ} \mathrm{C}$ & 29.9 & 29.9 & 29.9 & 29.9 \\
Compliance & $\checkmark$ & $\times$ & $\times$ & $\times$ \\
PMV with elevated air & 0.45 & 0.88 & 0.94 & 1.28 \\
PPD with elevated air, $\%$ & 9 & 22 & 24 & 39 \\
Sensation & Neutral & Slightly warm & Slightly warm & Slightly warm \\
SET, ${ }^{\circ} \mathrm{C}$ & 27.0 & 29.5 & 29.2 & 31.4 \\
Drybulb temp at still air, ${ }^{\circ} \mathrm{C}$ & 26.5 & 26.8 & 27.8 & 28.0 \\
Cooling effect, ${ }^{\circ} \mathrm{C}$ & 3.4 & 3.1 & 2.1 & 1.9 \\
Air speed, $\mathrm{m} / \mathrm{s}$ & 0.9 & 0.9 & 0.4 & 0.4 \\
\hline \hline Note. Result calculated from CBE thermal comfort tool [24] & &
\end{tabular}

Note. Result calculated from CBE thermal comfort tool [24]

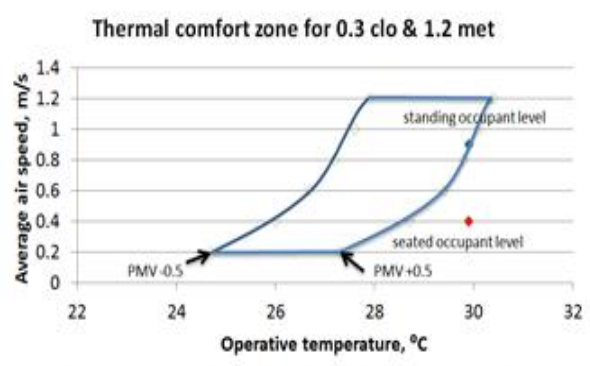

(a)Test room thermal condition for standing and seated occupant. (0.3 clo \& 1.2 met)

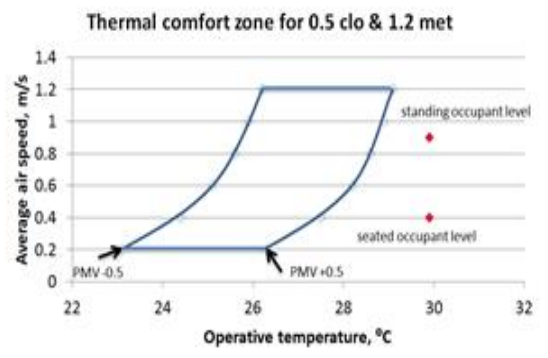

(b) Test room thermal condition for standing and seated occupant. (0.5 clo \& 1.2 met)

Fig. 8. Graphical representation of test room thermal condition against the thermal comfort zone by clothing insulation and metabolic rate value

It is shown that at standing occupant level, the test room was able to improve the base case PMV value of 2.3 down to less than 0.5 which is the acceptable PMV value. This is possible with the use of ceiling fan that provide air movement with speed up to $0.9 \mathrm{~m} / \mathrm{s}$ in the test room. This is also true for an assumed metabolic rate of 1.2 and clothing insulation value of 0.3 . The thermal condition of the test room during the cooling mode was suitable for an occupant with light clothing such as $T$ shirts and shorts (0.3 CLO) while the metabolic rate of 1.2 corresponds to occupant in a state of sedentary activity such as standing in a relax state. However for clothing insulation value of 0.5 or greater, the test room could not provide the required PMV value. This simply means thicker clothes would make the occupants thermally uncomfortable.
On the contrary, at the seated occupant level where the air speed is about $0.4 \mathrm{~m} / \mathrm{s}$, the thermal condition of the test room failed to meet the required PMV for clothing insulation value of 0.3 or greater. The usage of the radiant ceiling panel with air movement lower than $0.4 \mathrm{~m} / \mathrm{s}$ was not able to provide the required PMV value. Even though the resulting PMV value did improve significantly compare to the base case PMV value, however the occupant was still deemed to be in a slightly warm state with PMV ranging from 0.9 to 1.3 . The test room air temperature and the cooling effect of the air movement with speed up to $0.4 \mathrm{~m} / \mathrm{s}$ were not sufficient to provide acceptable thermal condition.

In view of the type of activities that is being done in the room and clothing insulation level, thermal comfort

could be achieved in the test room provided that the air 
speed was increased to a certain level. This can be demonstrated in the following Table 3. The table shows that higher air movement is needed for the given activities type and clothing insulation level to be inside thermal comfort zone. However unlike domestic activities like cooking and cleaning, high air speed in office environment is not desirable due to the work nature therefore variable such as operative temperature should be further lowered in order to comply with the minimum PMV.

TABLE 3

MINIMUM AIR SPEED REQUIREMENT TO ACHIEVE THERMAL COMFORT FOR HOME AND OFFICE ACTIVITIES

\begin{tabular}{lcc}
\hline \hline Thermal Comfort Parameter & \multicolumn{2}{c}{ Activities } \\
\cline { 2 - 3 } & Cooking, House Cleaning & Office Activities \\
\hline MET & $1.6-2.0$ & $1.0-1.2$ \\
CLO & 0.3 & 0.6 \\
Operative temperature, ${ }^{\circ} \mathrm{C}$ & 29.9 & 29.5 \\
Compliance & $\checkmark$ & $\checkmark$ \\
PMV with elevated air & 0.5 & 0.5 \\
PPD with elevated air, $\%$ & 10 & 10 \\
Sensation & Neutral & Neutral \\
SET, ${ }^{\circ} \mathrm{C}$ & 27.6 & 27.6 \\
Drybulb temp at still air, ${ }^{\circ} \mathrm{C}$ & 23.7 & 25.5 \\
Cooling effect, ${ }^{\circ} \mathrm{C}$ & 6.2 & 4.4 \\
Air speed, $\mathrm{m} / \mathrm{s}$ & 1.9 & 4.3 \\
\hline \hline
\end{tabular}

Note. Result calculated from CBE thermal comfort tool [24]
It should also be noted that the initial water temperature of the chill water tank used in the experiment were not up to its full potential as cooler water temperature is achievable through night cooling process in climatic region like Malaysia [26]. Therefore it is very likely that lower indoor temperature and better PMV value could be achieved after all. Further significant improvement is possible if the wall surface in the test room were converted to cooling surface as well. Providing more cooling surface area in the test room would increase the overall cooling capacity of the radiant system thus allowing more heat to be absorbed from the test room. This in turn will give better leverage in lowering the operative temperature that should positively impact the PMV value.

In this study the energy usage for the radiant cooling system was also evaluated. Table 4 shows a simple calculation step to estimate the annual energy usage for both radiant and air system that was applied on a typical single storey residential building with three bedrooms. All bedrooms and living room are assumed to be air conditioned in the calculation.

TABLE 4

ESTIMATION OF ANNUAL ENERGY SAVINGS FROM RADIANT COOLING SYSTEM

\begin{tabular}{|c|c|c|c|c|c|}
\hline \multirow[t]{2}{*}{ No } & \multirow{2}{*}{$\begin{array}{l}\text { Calculation Step } \\
\text { for Energy Use Estimate }\end{array}$} & \multicolumn{3}{|c|}{ System Type } & \multirow[t]{2}{*}{ Remark } \\
\hline & & $\begin{array}{l}\text { Radiant Cooling } \\
\text { with Night } \\
\text { Cooling System }\end{array}$ & $\begin{array}{c}\text { Non Inverter } \\
\text { Type Air } \\
\text { Conditioning System } \\
\end{array}$ & $\begin{array}{c}\text { Inverter Type } \\
\text { Air Conditioning } \\
\text { System }\end{array}$ & \\
\hline 1 & Determine energy consumption, kWh & & & & $\begin{array}{l}\text { i. Energy consumption for } 3 \\
\text { bedrooms and a living room } \\
\text { ii. It is assumed that air system will operate } \\
\text { at full load condition }\end{array}$ \\
\hline & a.Water pump & 0.45 & & & For radiant system \\
\hline & b.Ceiling fan & 0.24 & & & For radiant system \\
\hline & c.Split unit & & 5.1 & & $\begin{array}{l}\text { i. Non inverter cooling capacity rating } \\
\text { at full load operation }=1.28 \mathrm{kWh} / \mathrm{unit}\end{array}$ \\
\hline 2 & Total Operating hours per day & 14 & 8 & 8 & $\begin{array}{l}\text { As per calculation guideline } \\
\text { from Malaysian Energy Commision }\end{array}$ \\
\hline & Day-time (hrs) & 8 & 8 & 8 & $\begin{array}{l}\text { system cooling from } 1 \mathrm{pm} \text { to } \\
7 \mathrm{pm} \text { during which } \\
\text { peak indoor temperature }\end{array}$ \\
\hline & Night-time (hrs) & 6 & & & $\begin{array}{l}\text { cooling duration varies according } \\
\text { to tank water temp and night } \\
\text { Ambient air temperature }\end{array}$ \\
\hline 3 & Total kWh/day & 10 & 41 & 15 & \\
\hline 4 & Total kWh/year & 3526 & 14950 & 5572 & $\begin{array}{l}\text { Inverter type energy } \\
\text { consumption as reported by } \\
\text { Malaysian Energy Commission } \\
\text { for selected brand }\end{array}$ \\
\hline 5 & Local power tariff (RM) & 0.30 & 0.30 & 0.30 & \\
\hline 6 & Annual cost (RM) & 1057.77 & 4485.12 & 1671.60 & \\
\hline 7 & Monthly cost (RM) & 88.15 & 373.76 & 139.30 & \\
\hline 8 & Radiant system annual saving & $76 \%$ & & & $\begin{array}{l}\text { Value in comparison to non-inverter } \\
\text { type air conditioning system }\end{array}$ \\
\hline 9 & Radiant system annual saving & $37 \%$ & & & $\begin{array}{l}\text { Value in comparison to inverter type } \\
\text { air conditioning system }\end{array}$ \\
\hline
\end{tabular}


Apart from energy to run the fans for forced air movement, the radiant system also require electrical energy to power up the pumping set for water circulation in the night cooling loop and day cooling loop. Depending on the tank water temperature rise every time after day time cooling, the operating hours of the pump set at night may vary. Short hours of night cooling circulation may be needed if the temperature rise in the tank is minimal whereas longer hours would be needed to cool down the tank water with high temperature rise. For this energy calculation, an average value of 6 hours of night time cooling is applied. For the sake of energy comparison discussion it was also assumed that all three bedrooms including the living room of the house was air conditioned simultaneously. The day time cooling hours for both systems was taken to be about 8 hours. The calculation showed that the radiant cooling system was able to give significant energy saving of $76 \%$ of the cost to operate a non inverter air system a year and about $37 \%$ in comparison to an inverter type air conditioning system. This level of saving is not impossible as the radiant system requires only some amount of energy to run the pump set to circulate water whereas for an air system, high electricity energy is required to run electrical compressor of a split unit to provide indoor cooling.

\section{PRACTICAL IMPLICATION OF STUDY}

The findings from the experiment work at this stage have shown that the radiant system used in combination with passively night cooled water have some potential to be applied in local residential house to provide acceptable thermal comfort while benefitting from the reduced energy consumption. Other variant of low energy cooling technologies which apply night cooling have also shown the same criteria where the level of thermal comfort provided are acceptable and that the life cycle cost of such system is less than the conventional system [7]. The system under study here would be an attractive choice among the energy conscious building owner in place of the conventional air conditioning system which is used widely in this region. However further test should be done to show the full potential of the radiant cooling with night cooled water in term of its building thermal comfort performance as well as the energy saving that it offers. The cooling impact could be magnified if more surfaces in the room are converted into a radiant cooling surface and a lower water temperature is used to charge the radiant surfaces in order to have a cooler heat exchange surfaces. However it should be noted that the surface tem- perature of the radiant panel should be kept above the dew point so as to avoid mold and mildew problems which is a primary concern normally associated to the use of cooled surface in hot and very humid region like Malaysia. The water temperature from the night cooling process in this experiment was near the dew point temperature and that the resulting radiant surface temperature did not experience condensation or dripping. Consequently the radiant panel would lose its cooling capacity as shown in Figure 7. This is in agreement with other study by [37, 38, 39, 40]. Cooler water could be supplied provided that the humidity of the air in the room is low. Lowering of humidity could be done mechanically otherwise not needed in country with dry climate.

Another aspect of the experiment work worth mentioning here is the custom built radiant panel and the easily assembly of night cooling rig. Providing a cheaper and easy to get radiant cooling components as well as night cooling apparatus is an added advantage that would stir the interest of building owners to adapt a green and sustainable technology. The reduced energy cost in the system life cycle as shown in this study is also another significant point that makes the system more attractive. The future for such system as an alternative to the conventional cooling system in the country is great as the passive radiant cooling system clearly claim advantage in energy savings as one of its benefits [20]. On another hand, around 60\% installation cost saving is anticipated when using panel constructed using locally available alternative material over the more expensive imported radiant panels [21] which gives a competitive edge to the local panels to be applied widely in the local markets.

\section{CONCLUSION}

Experimental work on a PVC based tubing radiant ceiling panel installed in a test room is presented here. The ceiling radiant panel was able to lower the indoor temperature of the test room while improving the indoor thermal comfort to a limited extent. The limited cooling capability of the radiant ceiling is mainly due to the smaller surface area in relation to the much greater surface area of all the walls and floor combined. The non-active surfaces of the walls need to be insulated so as to reduce the transmitted heat gain through the wall and into the test room. Excessive transmitted heat through the wall would render the radiant cool ceiling inadequate to provide indoor cooling therefore the wall heat gain transmission should be controlled 
as much as possible through proper insulation work. On the other hand if cooler water is circulated in the radiant ceiling panel, the cooling performance would be improved as cooler water allows more heat from the test room to be absorbed. However use of chill water below $24^{\circ} \mathrm{C}$ would lead to surface condensation and impair the performance of the radiant ceiling panel thus usage of cooler water temperature should be checked. Another component in the test room which needs to be provided is the forced air movement provided by the ceiling fan. This is crucial in order to meet the targeted PMV value. The test has demonstrated the cooling capacity of the radiant ceiling panel to some degree by utilizing passively night cooled water. Therefore further test need to be done in all surface cooling mode which will incorporate room wall surfaces in addition to the ceiling panel to provide radiant cooling. The energy saving potential for this system is very high as it combines active and passive method of cooling to maintain a desirable indoor thermal comfort that meets the minimum thermal comfort standard. However use of this ceiling cooling only mode could only deliver room thermal condition which is barely within the specified thermal comfort zone and that it requires high air movement. In this case the air system cooling would still be a desirable choice as it could provide better room thermal condition even though at higher energy cost. The preference could shift from air only cooling system to the radiant cooling system if further test could be conducted for other configuration such as the all surface cooling mode in the future to prove its effectiveness. Lower construction and installation cost as well as the life cycle cost of the night cooled water coolant radiant system would give an added advantage to make this green technology a favorite among building owners in Malaysia.

\section{REFERENCES}

[1] R. Hyde, "Bioclimatic housing innovative design for warm climate," London, UK: Earthscan, 2008.

[2] A. Gregor, "Bioclimatic design: US green building council," 2014 [Online]. Available: goo.gl/BDm1xk

[3] R. D. Watson and K.S. Chapman, "Radiant heating and cooling handbook," New York, NY: McGraw-Hill, 2002.

[4] L. S. Nielsen, "Building integrated system design for sustainable heating and cooling," REHVA Journal, vol. 3, no. 5, pp. 24-27, 2012.

[5] A. S. Binghooth and Z. A. Zainal, "Performance of desiccant dehumidification with hydronic radiant cooling system in hot humid climates," Energy and Buildings,

ISSN: 2414-4592

DOI: $10.20474 /$ jater-3.5.5 vol. 51, pp. 1-5, 2012.

DOI: $10.1016 /$ j.enbuild.2012.01.031

[6] D. G. L. Samuel, S. M. S. Nagendra and M. P. Maiya, "Passive alternatives to mechanical air conditioning of building: A review," Building and Environment, vol. 66, pp. 54-64, 2013. DOI: 10.1016/j.buildenv.2013.04.016

[7] M. Zimmermann and J. Andersson, "Case studies of low energy cooling technologies," 1998 [Online]. Available: goo.gl/dBVr4a

[8] A. H. H. Ali, I. M. S. Taha and I. M. Ismail, "Cooling of water flowing through a night sky radiator," Solar Energy, vol. 55, no. 4, pp. 235-253, 1995.

DOI: $10.1016 / 0038-092 \times(95) 00030-u$

[9] A. H. H. Ali, "Passive cooling of water at night in uninsulated open tank in hot arid areas," Energy Conversion and Management, vol. 48, no. 1, pp. 93-100, 2007. DOI: /10.1016/j.enconman.2006.05.012

[10] P. D. Dan and J. C. V. Chinnappa, "The cooling of water flowing over an inclined surface exposed to the night sky," Solar \& Wind Technology, vol. 6, no. 1, pp. 41-50, 1989. DOI: $10.1016 / 0741-983 x(89) 90036-2$

[11] N. Chotivisarut, A. Nuntaphan and T. Kiatsiriroat, "Seasonal cooling load reduction of building by thermosyphon heat pipe radiator in different climate areas," Renewable Energy, vol. 38, pp. 1, pp. 188-194, 2012. DOI: $10.1016 /$ j.renene.2011.07.021

[12] T. Runsheng, Y. Etzion and E. Erell, "Experimental studies on a novel roof pond configuration for the cooling of buildings," Renewable Energy, vol. 28, no. 10, pp. 1513-1522, 2003.

DOI: $10.1016 / \mathrm{S0960-1481(03)00002-8}$

[13] E. Erell and Y. Etzion, "Radiative cooling of buildings with flat-plate solar collectors," Building and Environment, vol. 35, no. 4, pp. 297-305, 2000.

DOI: $10.1016 /$ S0360-1323(99)00019-0

[14] J. Sima, O. Sikula, K. Kosutova and J. Plasek, "Theoretical evaluation of night sky cooling in the Czech Republic," Energy Procedia, vol. 48, pp. 645-653, 2014.

DOI: 10.1016/j.egypro.2014.02.075

[15] G. Heidarinejad, M. Farmahini and S. Delfani, "Investigation of a hybrid system of nocturnal radiative cooling and direct evaporative cooling," Building and Environment, vol. 45, no. 6, pp. 1521-1528, 2010.

DOI: 10.1016/j.buildenv.2010.01.003

[16] L. T. D. Ha and K. M. T. Tsai, "Numerical study on optimization of wooden-steel hybrid beams base on shape factor of steel component," International Journal

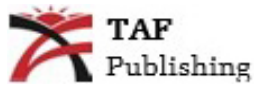


of Technology and Engineering Studies, vol. 1, no. 2, pp. 53-62, 2015. DOI: 10.20469/ijtes.40004-2

[17] S. Zhang and J. Niu, "Cooling performance of nocturnal radiative cooling combined with Microencapsulated Phase Change Material (MPCM) slurry storage," Energy and Buildings, vol. 54, pp. 122-130, 2012.

DOI: $10.1016 /$ j.enbuild.2012.07.041

[18] R. T. Dobson, "Thermal modelling of a night sky radiation cooling system," Journal of Energy in South Africa, vol. 16, no. 2, pp. 20-31, 2005.

DOI: $10.17159 / 2413-3051 / 2017 / v 28 i 1 a 1550$

[19] B. Azhaili, H. I. Siti, A. Mohammad Omar and K. B. Ooi, "A passive malaysian residential building with a hydronic radiator," International Journal of Recent Research and Applied Studies, vol. 7, no. 4, pp. 380-389, 2011.

DOI: $10.1016 /$ j.proeng.2015.09.024

[20] K. H. Sor and S. K. Han, "A critical evaluation of radiant cooling utilization in Malaysia: The sheffield hallam university built environment research transactions," 2013 [Online]. Available: goo.gl/nKFGr5

[21] S. H. Ibrahim, A. Baharun and W. A. W. Z. Abidin, "Performance of low cost alternative radiant cooling panel in Malaysia," International Journal of Applied Engineering Research, vol. 11, pp. 11, pp. 7333-7342, 2016.

DOI: $10.4028 / w w w . s c i e n t i f i c . n e t / j e r a .26 .86$

[22] American Society of Heating, Refrigerating and AirConditioning Engineers (ASHRAE), "Standard 55-2013 thermal environmental conditions for human occupancy," 2013 [Online]. Available: goo.gl/Kibbo9

[23] International Organization for Standardization (ISO), "EN ISO 7730 ergonomics of the thermal environment-analytical determination and interpretation of thermal comfort using calculation of the PMV and PPD line]. Available: goo.gl/UWkZn7

[24] H. Tyler, S. Stefano, P. Alberto, M. Dustin and S. Kyle, "CBE thermal comfort tool," 2013 [Online]. Available: goo.gl/7mSyfq

[25] International Organization for Standardization (ISO), "ISO 7726 ergonomics of the thermal environmentinstruments for measuring physical quantities," 1998 [Online]. Available: goo.gl/FxBfM4

[26] N. V. Baker, "Passive and low energy building design for tropical island climates," London, UK: Commonwealth Secretariat, 1987.

[27] M. S. Imran, A. Baharun, S. H. Ibrahim and W. A. W. Z. Abidin, "Nocturnal cooling of water as free cooling source for building indoor radiant cooling in Malaysian indices and local thermal comfort criteria," 2005 [On-

climate," in Proceedings of International Conference on Applied Mechanics, Mechanical and Materials Engineering, Pennsylvania, PA, 2016.

[28] M. S. Imran, A. Baharun, S. H. Ibrahim and W. A. W. Z. Abidin, "Renewable indoor radiant cooling and earth tube heat exchanger hybrid for thermal comfort improvement," Journal of Building Performance, vol. 7, no. 1, pp. 56-71, 2016.

[29] S. H. Ibrahim and J. A. Tinker, "Improvements to thermal comfort in low-income housing in Malaysia," In Proceedings of Conference on Sustainable Building South East Asia, Kuala Lumpur, Malaysia, 2005.

[30] S. Rajeh, "Wind ventilation of terrace housing in Malaysia," In Proceedings of ISI-UTM International Convention and Exposition, Kuala Lumpur, Malaysia, 1994.

[31] A. M. Nugroho, "A preliminary study of thermal environment in Malaysia's terraced houses," Journal of Economics and Engineering, vol. 2, no. 1, pp. 25-29, 2011.

[32] H. M. Kamar, N. Kamsah, M. M. Tap and K. A. M. Salimin, "Assessment of thermal comfort in a naturally ventilated residential terrace house," In Proceedings of The $4^{\text {th }}$ International Meeting of Advances in Thermofluids, Melville, N.Y, 2012. DOI: 10.1063/1.4704224

[33] M. G. Normah, K. Y. Lau and S. Mohd. Yusoff, "Thermal analysis of Malaysian double storey housinglow/medium cost unit," In Proceedings of The $4^{\text {th }}$ International Meeting of Advances in Thermofluids, Melville, N.Y, 2012. DOI: 10.1063/1.4704257

[34] H. Djamila, C. M. Chu and S. Kumaresan, "Field study of thermal comfort in residential buildings in the equatorial hot-humid climate of Malaysia," Building and Environment, vol. 62, pp. 133-142, 2013.

DOI: $10.1016 /$ j.buildenv.2013.01.017

[35] I. Hussein, M. H. A. Rahman and T. Maria, "Field studies on thermal comfort of air-conditioned and non airconditioned buildings in Malaysia," In Proceedings of ICEE $3^{\text {rd }}$ International Conference on Energy and Environment: Advancement Towards Global Sustainability, Malacca, Malaysia, 2009.

DOI: 1109 /ICEENVIRON.2009.5398622

[36] A. T. Nguyen, M. K. Singh and S. Reiter, "An adaptive thermal comfort model for hot humid South-East Asia," Building and Environment, vol. 56, pp. 291-300, 2012. DOI: $10.1016 /$ j.buildenv.2012.03.021

[37] D. Scheatzle, "Combining radiant and convective systems with thermal mass for a more comfortable home," ASHRAE Transactions, vol. 112, no. 1, pp. 253-268, 2006. 
[38] A. Ameen and K. Mahmud, "Desiccant dehumidification with hydronic radiant cooling system for airconditioning applications in humid tropical climates," ASHRAE Transactions, vol. 111, no. 2, pp. 225-237, 2005.
[39] B. Olesen, "Radiant floor cooling systems," 2008 [Online]. Available: goo.gl/4yzwhi

[40] S. Qingyun and H. Jing, "Research on suitable application sites of radiant cooling system," Energy Procedia, vol. 14, pp. 1002-1007, 2012.

DOI: $10.1016 /$ j.egypro.2011.12.1046

— This article does not have any appendix. — 